\title{
Memória e (re)existência: a trajetória intercultural da Ação Saberes Indígenas na Escola
}

\author{
Memory and (re)existence: the intercultural path of the \\ program Indigenous Knowledge at School
}

\author{
Bruno Ferreira ${ }^{1}$ \\ Magali Mendes de Menezes² \\ Maria Aparecida Bergamaschi
}

DOI: http://dx.doi.org/10.20435/tellus.vi43.704

\begin{abstract}
Resumo: A Ação Saberes Indígenas na Escola produz movimentos importantes na direção da escola indígena sonhada. O presente texto narra a intensidade, as contradições, alegrias e dores da relação entre agentes da universidade e das comunidades Kaingang e Guarani que participam deste programa. A reflexão, de autoria de um professor formador Kaingang e de duas professoras não indígenas coordenadoras institucionais da Ação na Universidade Federal do Rio Grande do Sul, permeou também as vivências aqui relatadas e suas contribuições para compreender os sentidos da interculturalidade nos diálogos, no trabalho nas escolas indígenas, nas comunidades e na universidade. $O$ debate sobre a afirmação/recuperação das línguas, a elaboração dos materiais didáticos, as reflexões sobre a escola indígena e a organização das lutas por meio do espaço desta Ação reverberam em aprendizagens aqui narradas, como memória e (re) existência da caminhada intercultural.
\end{abstract}

Palavras-chave: saberes indígenas; educação escolar indígena; escola; (re)existência; interculturalidade.

\begin{abstract}
The program Indigenous Knowledge at School has produced important movements in the quest for a dreamed indigenous school. The present text features a narrative on the intensity, the contradictions, joys, and pains of the relationship between the university and the Kaingang and Guarani communities who participate in this program. The reflections - by a Kaingang teacher and two non-indigenous teachers who coordinate the program at the University - are also present in the experiences reported here, as those teacher's contributions to understand the meanings of interculturality in the
\end{abstract}

1 Instituto Estadual de Educação Indígena Angelo Manhká Miguel, Terra Indígena Inhacorá, São Valério do Sul, RS, Brasil.

2 Universidade Federal do Rio Grande do Sul, Porto Alegre, RS, Brasil. 
dialogues, in the everyday work at the indigenous schools, communities, and university. The debate on such themes as the affirmation, recognition, and revival of indigenous languages; the elaboration of teaching materials; reflections on the indigenous school; and the organization of struggles built during the program reverberates in the learnings here narrated, such as memory and the (re)existence of an intercultural path.

Keywords: Indigenous Knowledge at School; indigenous education; indigenous school; (re)existence; interculturality.

\section{INTRODUÇÃO}

Em que língua se faz possível o diálogo intercultural? Se a terra em que pisamos atravessa nossa fala, onde teremos que colocar nossos pés para falar com o Outro? Queremos, nesta reflexão, trazer fragmentos de uma relação tecida entre professores indígenas e não indígenas que fizeram parte da Ação Saberes Indígenas na Escola ao longo de cinco anos (2014-2019). Os momentos de profunda aprendizagem vividos mutuamente foram possibilitados também por nossa condição: de ser e não ser indígena. O exercício de diálogo fez com que pudéssemos pensar inclusive os sentidos do próprio diálogo, na relação constante e desafiante de estar simplesmente diante do Outro. Pensamos aqui a categoria de Outro não a partir de uma visão essencialista, em que a alteridade passa a ser percebida na relação com um sujeito colocado como Absoluto e que tem o poder de dizer outro. Outro somos todos nós, na medida em que estamos em relação e trazemos nossos mundos, linguagens, racionalidades.

Entre o espaço da universidade e da aldeia buscou-se construir pontes possíveis para fazer comunicar mundos distantes e, ao mesmo tempo, marcados pela violência histórica que constituiu processos de colonização, vividos até hoje. Foi necessário então, iniciar desfazendo imagens, formas, lugares, pensamentos. Não havia um único lugar (mesmo que a proposta fosse pensar a escola), pois a perspectiva intercultural foi nos ensinando a necessidade de estar entrelugares, em processos de deslocamentos constantes. Aos poucos, na vivência concreta de se aproximar do mundo do Outro, buscou-se palavras, compreender desde os silêncios, (re)aprender. Sabíamos que a palavra traria a memória dos mais velhos, presentes todo tempo em cada coisa dita, na lembrança, no pensamento que se desenhava. Rompeu-se assim, com metodologias prontas, pois se apresentavam sempre como a priori impossíveis de serem realizados quando se busca uma 
relação intercultural, em sintonia com o poema de Antônio Machado que nos diz, "caminhante, não há caminho, se faz caminho ao andar" ${ }^{3}$. Percebeu-se que a palavra então (ora na língua originária Kaingang e Guarani, ora em Português) foi se tecendo no encontro do indígena com seu povo e a autoria de cada palavra não era mais individual, mas coletiva. As palavras, ensinamentos que não possuíam bibliografias, eram as palavras vivas dos mais velhos que os indígenas encontravam. Contudo, pensar o letramento, numeramento e todo universo da escola continuava sendo, em muitos momentos, um mundo ainda estranho para uma cultura da oralidade. Qual seria o sentido de uma escola indígena? Esta questão permeou todos os momentos de formação, pois era necessário recolocá-la constantemente para que pudéssemos pensar como deveria ser esta escola indígena e, não simplesmente, uma escola para indígenas.

A escola como lugar da escrita, da língua que precisa encontrar seu alfabeto, pensar formas de escrevê-lo eram questões trazidas e que foram mostrando que a palavra poderia ser falada (mesmo que fosse escrita). Paradoxo que se mostrou na própria confecção dos materiais didáticos pedagógicos, que falavam por desenhos, registro de narrativas orais, palavras, mas também constituídos por espaços em branco. Foram momentos em que se discutiu qual a melhor forma de escrever, se deveria haver um alfabeto universal Kaingang e Guarani, ou se o alfabeto poderia respeitar as diferenças de pronuncia de cada comunidade. Era também importante refletir a utilização dos materiais nas escolas e nas comunidades indígenas. Havia a demanda de livros didáticos na língua originaria, que traziam a riqueza de serem feitos pelos professores indígenas. Contudo, sempre surgia a dúvida da real utilização destes materiais no dia a dia das escolas pelos professores, mostrando que a língua não cabe no espaço do papel. A escrita, desse modo, subverte as normas, os diálogos passam a ser conversas de como é possível (re)dizer o que só tem sentido na língua indígena. A escrita-palavra, criava poesia para trazer uma vida que não pode ser represada na folha do papel. Rodolfo Kusch, a respeito da poesia, nos fala,

[...] com a alfabetização se dá a fixação e a uniformização do sentido. Em suma, se instala um logos convencional que nada tem a ver com o logos não escrito que encerra

3 Cf. http://blogs.utopia.org.br/poesialatina/cantares-antonio-machado/. Consulta realizada em 23/08/2019. 
o sentido do existir indígena. Se nega então com a alfabetização a possibilidade do mecanismo do antidiscurso, porque se alfabetiza um aspecto do existir. É possível que isto se remedeie [destaque dos autores] enquanto a alfabetização vai acompanhada de algo, assim como um poetizar, a partir do alfabeto mesmo. O poético, ou seja, a poiesis, ou seja, a criação, poderia reatualizar o horizonte simbólico do indígena e, por conseguinte, reintegrar a totalidade de seu existir. (KUSCH, 1976, p. 112).

Kusch, filósofo argentino que escreveu sobre o pensamento popular e indígena, nos mostra que não podemos perder a poesia no diálogo intercultural. A poesia é capaz de trazer a existência o que, culturalmente, poderia estar ameaçado de deixar de existir. A poesia preenche o vazio intercultural, cria outras formas de diálogo, em que a palavra poética- aquela que não é feita de conceitos, mas de metáforas, como uma palavra sempre fora de lugar - permite que o Outro surja, dá espaço para que o Outro possa dizer-se. Isso acontece porque a palavra poética não é apertada, possui espaços, espaços de silêncio em que o invisível habita. Recordamos um trecho de filme $O$ Carteiro e o poeta, em que Pablo Neruda explica ao carteiro o que é metáfora: "Aqui é a ilha e o mar, e quanto mar, se sai de si mesmo a cada instante, diz que sim, que não, que sim, que não, um azul, em espuma, em galope, não pode estar quieto, me chamo mar, repete, pegando uma pedra sem tentar convencê-la [...]"4. Generosidade de um mar que bate na pedra, lapidando-a com o tempo, mas não quer convencê-la. Mar que vem e vai, mareando o pensamento na sua inconstância. Sentido da metáfora, ser inconstante e não definidora; o que essencializa, define, adere a forma e tudo que escapa a ela torna-se inadequado.

É preciso fazer do diálogo um espaço poético, em que a linguagem, mais do que definidora, possa ser mítica. Esta é a única forma de remediar a sua violência. Mas é importante destacar, como comenta Kusch na citação feita, que apenas é uma forma de remediar e não eliminar, pois a alfabetização a partir de outra cultura não indígena é uma tarefa da escola ocidental, contudo deve ser acompanhada por um processo de desalfabetização poética (feito mar que vai e vem). Aprender é, portanto, desaprender.

O que queremos aqui trazer, então, são alguns momentos de uma relação profunda junto aos indígenas Kaingang e Guarani. O mais importante neste

${ }_{4}$ Trecho extraído do seguinte endereço: http://www.youtube.com/watch?v=fbTmmx_579A. Consulta realizada em 10/08/2019. 
processo foi pensar esta relação como um não-lugar entre universidade-aldeia, aberto ao diálogo, feito mar que bate na pedra, sem buscar convencê-la. Nestes momentos não há mais lugar seguro. Muitas coisas ficaram incompreendidas, porque se precisava preservar o segredo. Os diálogos interculturais que nesta relação vivemos nos mostraram que era possível compreender o Outro sem, contudo, entendê-lo. A compreensão que advém não apenas da intelecção, mas da vida que contempla a emoção, o coração, como diz Rodolfo Kusch (2000). O autor nos mostra que, no pensamento indígena e popular, a afetividade é concebida como necessária para decisões inteligentes, que consideram o corazonar. Nessa perspectiva, o coração é entendido como corpo, como um todo que pertence ao estado interior do ânimo, elevado ao nível de uma faculdade psíquica. Diz Kusch que no pensamento ameríndio o coração tem o valor de um regulador intuitivo do juízo- racional e irracional, que vê e que sente. Ou seja, uma combinação de sujeito e objeto, que resulta num sujeito total, não fragmentado. Portanto, o coração entendido como o símbolo de integração e equilíbrio.

Nesse texto, produzido por um professor Kaingang e professoras da universidade, que coordenaram de forma compartilhada a Ação Saberes Indígenas na Escola, apresentamos aprendizagens comuns realizadas neste percurso, em muitas situações, aprendizagens interculturais que reverberam na universidade e nas comunidades e escolas Kaingang e Guarani. Aprendizagens que vão aos poucos transformando as pessoas e as instituições. São reflexões realizadas a partir da organização da formação continuada de professores indígenas que repercute nas escolas e nas comunidades Kaingang e Guarani, mas que também reverberam na instituição de ensino superior que teve a incumbência de coordenar esta ação.

\section{AS PROVOCAÇÕES COMO ABERTURAS AO PENSAR}

Trazemos, neste momento da escrita, algumas indagações de Dorvalino Refej Cardoso, professor do povo kaingang, que participou da 1a e 2a edição da Ação Saberes Indígenas na Escola - Núcleo UFRGS, como professor-formador. Em uma de suas falas, questionou o fato da universidade não ser intercultural, conquanto em muitos momentos possamos identificar ensaios de práticas interculturais, a academia está longe ainda de ser um espaço intercultural. Seu questionamento vem do fato de já ter sido investigado por diferentes pesquisadores, que chegavam 
em sua aldeia e absorviam conhecimentos de seu povo para assim escreverem seus textos. No entanto, Dorvalino questiona que não sabia nada sobre a vida dos pesquisadores que ali chegavam, nada de sua família, de suas histórias. Dorvalino, em muitos momentos, abria sua casa para alguém que desconhecia, bebia do saber de seu povo e não retornava mais para dividir, compartilhar o que produziu. São poucas as cumplicidades que se construíram nestas relações. Na academia, muitas vezes o tempo da relação torna-se o tempo da pesquisa. A coordenação da Ação Saberes Indígenas na Escola estava na Universidade e este era um desafio, pois era fundamental desconstruirmos a visão de uma universidade que leva conhecimentos para as comunidades indígenas, era fundamental que a universidade também aprendesse com os conhecimentos indígenas e que isso fosse capaz de transforar a própria universidade.

Dorvalino, formou-se em Pedagogia e decidiu cursar Mestrado em Educação e em sua dissertação buscou pensar a filosofia kaingang. Este é um aspecto importante, pois percebemos que a Ação Saberes Indígenas na Escola instigou muitos professores indígenas a entrarem na universidade, cursarem a academia, buscando uma formação nos cursos de Graduação e de Pós-Graduação. Ao pesquisar a filosofia kaingang, Dorvalino sempre se perguntava sobre o que era mesmo filosofia e se poderia chamar o conhecimento de seu povo de filosófico. Esta questão trazia toda a disputa que existe para legitimar o saber. Quando, por exemplo, falamos em cosmologia, saberes, ao invés de epistemologia, o que está em jogo não é apenas o modo como utilizamos uma expressão, mas o lugar de validade do conhecimento.

Portanto, reconhecer o pensamento de seu povo como filosófico, traduz a disputa histórica sobre o que é mesmo Filosofia. Dizemos que a filosofia é um objeto para si mesma, por isso não existe um único sentido para a Filosofia. Mas se tomarmos o sentido grego que inventou a palavra filosofia, esta significa "amor à sabedoria". Dorvalino, ao tomar conhecimento deste sentido afirma que "todo o pensamento Kaingang é filosofia, porque todo o pensamento se direciona ao amor". Ou seja, mais do que ser amor à sabedoria, é uma sabedoria do amor.

O pensador Raúl Fornet-Betancourt (2004), nos diz que a Filosofia surge de um ordenamento de saberes, de determinada organização do conhecimento. Esta possui uma profunda relação com a forma com que uma cultura compreende e 
organiza o mundo. A definição de Filosofia é, por isso, sempre normativa, composta desde uma constelação de saberes, ratificadora de um processo de ocidentalização do próprio ocidente. A Filosofia nasce na ordem ocidental como um processo de afirmação mesma do que se configura o ocidente. Todo movimento filosófico é marcado por este processo, possui suas normas, linguagem, sentido, e por mais que a experiência filosófica caminhe em direção ao desconhecido, este logo é capturado, decodificado, encontrando um sentido desde a lógica do universo filosófico. Destaca-se aqui o papel importante que exerce o sistema educacional que nos ensina, mais do que conteúdos, acima de tudo o modo como devemos fazer a experiência da aprendizagem.

É justamente esta armadura em que se encontra envolvida a Filosofia e do mesmo modo, a Educação, impedindo o diálogo intercultural. Para FornetBetancourt, não é "o saber filosófico, mas sua definição" (2004, p. 24) que impede a comunicação. A grande definição de filosofia (como ele faz referencia) nos afasta da experiência cotidiana, pois esta vem sempre filtrada e mediada pela grande definição filosófica. A interculturalidade nos coloca o desafio de recuperarmos a vida que palpita e vibra no cotidiano, nos exigindo um simples abrir-se a este contato. Com isso percebemos que não são os conceitos que dão sentido a vida, mas a vida que transborda e dá sentido aos conceitos. Poderíamos ainda dizer que, talvez, a experiência mais profunda e ex-posta de um sujeito com seu contexto nos conduz a uma experiência que não pode ser codificada conceitualmente. Desse modo, podemos chegar a um lugar que não seja mais conceitual, incapaz de traduzir o experienciado. Somente este fato já coloca em cheque a grande definição de filosofia imposta pelo ocidente. Quando falamos em filosofia intercultural temos que deixar aberta toda e qualquer definição de filosofia, pois definir é de certo modo, nos colocar dentro de um sistema normativo, que nos diz que para pensar, refletir é preciso definir. "A filosofia se converteu em um saber dentro de um sistema que tem sua própria língua, que cria suas próprias categorias, que coloca suas próprias metas e se faz autoreferencial [sic]" (FORNET-BETANCOURT, 2004, p. 24). A filosofia é, desse modo, grega, europeia ocidental e encontra-se aí toda a referência para pensar a filosofia. Nada pode escapar a este sistema. O diálogo intercultural, contudo, rompe a autorreferencialidade da filosofia, pois, ao invés de colocarmos ideias em diálogo, colocamos práticas contextuais feitas de memórias, histórias e projetos que, de alguma forma, podemos compartilhar com o outro. 
Dorvalino nos diz,

A organização kanhgág é diferente, somos todos irmãos, todos se organizam de um jeito só, a ideia, o pensamento é único. Hoje cada um se organiza de um jeito. O professor é pesquisador, tem que falar com os mais velhos, com o kujá. O espaço educativo não está na escola e sim onde vamos fazer nossas danças, nossos trabalhos espirituais. Estou com esta idade e aprendi pouco na escola. (Dorvalino Refej Cardoso, em 07/04/2014).

O que os indígenas aprendem com a Universidade? E o que a universidade aprende com os indígenas? Afinal, o que significa aprender dentro de uma relação intercultural? De que maneira a escola torna-se ume espaço de aprendizagens significativas para os indígenas? São algumas questões que perpassaram a Ação Saberes Indígenas na Escola.

\section{AS BRECHAS PARA UM VIVER INTERCULTURAL NA UNIVERSIDADE}

Catherine Walsh (2016) alerta sobre as brechas e as fissuras nas quais podemos pensar e atuar no mundo acadêmico, espaços que a ativista intelectual, como ela mesma se denomina, aprendeu a habitar, conquanto a monologia de uma construção fechada para o outro, para a pluriversidade. Nesse sentido, a Ação Saberes Indígenas na Escola pode ser pensada como uma brecha intercultural neste universo acadêmico que se diz e se faz, majoritariamente, no singular. Desde os primeiros movimentos para se constituir institucionalmente na universidade foi preciso abrir novos caminhos, atuar na contramão de uma pretensa normalidade que predomina e nomeia toda a diferença como estranha.

Pensar a brecha como uma oportunidade, como uma abertura, que mesmo estreita permite a germinação de outra cultura, de outro modo de pensar e por ela sair dos parâmetros impostos pelo conhecimento único, pela ciência moderna que se arroga como universal: aqui só se fala uma língua! Mas também podemos pensar a brecha como uma rocha sedimentar composta com muitos fragmentos que se aglutinam, fragmentos de origens diversas que se juntam, formando algo novo. A brecha que germina a Ação Saberes Indígenas - núcleo UFRGS, pensada e sentida como espaço de resistência e (re)existência, fragmentos que se aglutinam e se (re)inventam em um novo espaço de existência, em movimentos que dispõe também a reinvenção da universidade. Brecha, que como fresta atravessa 
o espaço acadêmico que se apresenta homogêneo, mas que também se renova ao acolher esse outro ou esses outros que insistem e resistem. "La re-existencia apunta a descentrar las lógicas establecidas para buscar en las profundidades de las culturas [...] las claves de formas organizativas, de producción, alimentarias, rituales y estéticas que permitan dignificar la vida y re-inventarla para permanecer transformándose" (ALBAN ACHINTE, 2017, p. 455).

Igualmente nos inspira Daniel Mato (2008), ao considerar a colaboração intercultural imprescindível para superar e até mesmo suplantar o que ainda é crença para uma parte significativa da academia, referenciada nesses supostos conhecimentos universais. Seguimos nas fissuras que acolhem institucionalmente a Ação Saberes Indígenas na Escola, a partir do ingresso da Universidade Federal do Rio Grande do Sul na rede nacional de formação continuada de professores indígenas, como possibilidade concreta de afirmar as epistemologias ameríndias e buscar a ampliação dos espaços de articulação e diálogo intercientífico. A universidade, ao tornar possível uma ação de extensão, que no seu programa desenvolve pesquisa e ensino e tem como base os saberes e os conhecimentos indígenas, trazido por seus sábios, por seus professores, torna a interculturalidade possível, mesmo que na fissura, na homogeneidade rasgada pelos sons do mbaraka (chocalho) que acompanha o ritual da abertura de encontro, em que a reza faz parte do aprender e do ensinar.

Nesta ação vivenciamos a colaboração intercultural que prescindiu dos conhecimentos Guarani e Kaingang na formação de seus professores, representado pelos sábios que fazem parte institucional do programa, como bolsistas pesquisadores e formadores, mas também pelas pesquisas desenvolvidas pelos professores, nos grupos de orientação, nas suas escolas, envolvendo comunidades. Buscar, nos conhecimentos próprios, elementos para afirmar a escola e, principalmente, para produzir materiais didáticos é um dos objetivos da Ação Saberes Indígenas na Escola. Embora a finalidade principal deste movimento seja o de alimentar as escolas indígenas com seus próprios saberes, a universidade se sentiu e se sente afetada. Acostumada a dizer e validar conhecimentos produzidos desde uma perspectiva ocidental, norte-eurocêntrica, desta vez pode vivenciar o que Boaventura de Souza Santos (2010) nomeia como ecologia de saberes, validando saberes outros advindos do patrimônio de conhecimentos Kaingang e Guarani. Diz 
o autor (p. 57) que "se ha realizado un epistemicidio masivo en los últimos cinco siglos, por el que una inmensa riqueza de experiencias cognitivas se han perdido. Para recuperar algunas de estas experiencias, la ecología de saberes recurre a una traducción intercultural, su rasgo más característico".

Porém, são movimentos provocativos dentro de um espaço acadêmico arrumado, que desacomoda, desarruma e faz aflorar contradições: pode haver uma disposição ético-política para o diálogo intercultural, porém há limites administrativos e burocráticos que barram e impedem a fluência das ações. Abrir espaço para a formação de professores Kaingang e Guarani, conforme previsto na concepção disposta na portaria e nas orientações legais de sua criação ${ }^{5}$ é lidar com o inusitado na universidade; é abrir brechas para os saberes e conhecimentos do mundo não letrado dos sábios de cada povo que passam a ser professores dos professores indígenas. É acolher a sabedoria de um velho kaingang, como seu Jorge Garcia, que declara "minha universidade foi a mata" e, distanciado do mundo letrado, desconhecendo ferramentas que hoje já são comuns em sua aldeia, como a escrita e a leitura, ensina aos professores os princípios básicos de uma educação própria, que referenda a mata e o rio, que referenda os saberes ancestrais. Seu Jorge Garcia não apresenta um título acadêmico em seu currículo, mas traz as marcas do reconhecimento de um coletivo que o denomina Kujá, ou seja, o sábio, capaz de transmitir conhecimentos primordiais para os professores Kaingang que estudam, discutem e pensam um projeto de escola menos colonial e mais adequada ao sonho de "uma escola específica e diferenciada de verdade", como repetem nos encontros de formação. Seu Jorge Garcia traz a língua Kaingang em sua integralidade, no canto, na reza, na saudação e nos saberes, fazendo a universidade se adequar a outro idioma, a outros conhecimentos ausentes e negados. A mata, escola do kujá, vem para a universidade com sua força incontrolada que insiste e aproveita a fissura para brotar, para disseminar suas raízes, espalhando-se para além da fresta que fixou a vegetação ao germinar.

5 Portaria n. 1061 de 30 de outubro de 2013, que institui a Ação Saberes Indígenas na Escola na qual, o Ministério da Educação, por intermédio da Secretaria de Educação Continuada, Alfabetização, Diversidade e Inclusão-SECADI/MEC, e em regime de colaboração com estados, Distrito Federal, municípios e instituições de ensino superior (destaque dos autores) reafirma o compromisso com a educação escolar indígena na educação básica (BRASIL, 2013). 
Figura 1 - Kujá Jorge Garcia em um momento de formação

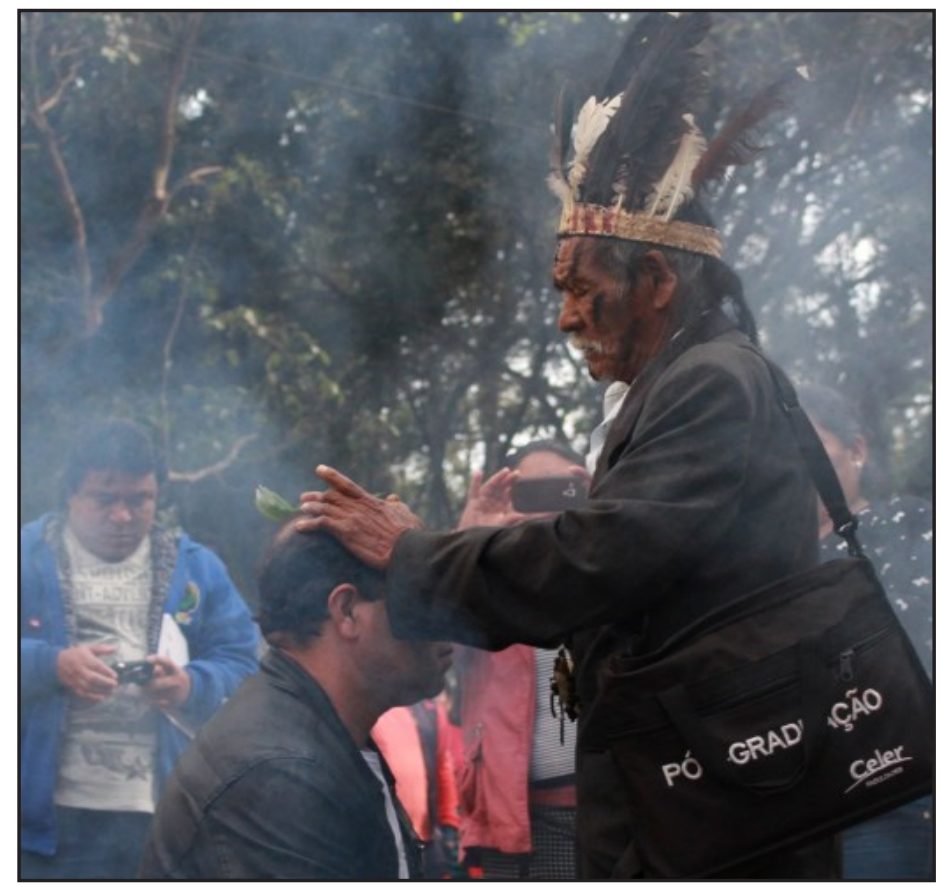

Fonte: Arquivo da Ação Saberes Indígenas na Escola/UFRGS.

Assim inicia a Ação Saberes Indígenas na Escola há mais de cinco anos na Universidade Federal do Rio Grande do Sul. Um trabalho intenso e marcante em todas as etapas da ação passou a ser realizado, desde os encontros inicias, com a finalidade de compreender a dinâmica dada pelas diretrizes legais que a instituíram, bem como os contextos locais que configuram as escolas Kaingang e Guarani, circunscritas à Secretaria de Estado da Educação do Rio Grande do Sul. As Terras Indígenas destes povos se espraiam por todo o estado, desde pequenos espaços com menos de dez hectares até algumas poucas terras com território considerável e com condições de vida mais adequado. Concordam que é da terra que vem a força para continuarem seus modos de vida, sua educação própria. Lamentam pelo tanto que perderam e perdem com a colonização que mostra sua cara diariamente e que tem na escola um ponto forte de apoio. Como transformar esta escola?

Em todas as terras Kaingang há, pelo menos uma escola, assim como em quase todas as terras Guarani. São, ao todo, 92 escolas de ensino fundamental no 
Rio Grande do Sul: 86 pertencentes à rede estadual e seis a redes municipais; 58 Kaingang e 34 Guarani, todas situadas em terras indígenas (Censo Escolar 20176). No início da Ação Saberes Indígenas na Escola fizemos um levantamento sobre o uso das línguas originárias nas comunidades e, principalmente nas escolas. Segundo estimativas da Secretaria de Estado da Educação, nas 58 escolas kaingang, $30 \%$ dos alunos tem a língua originária como primeira e única até ingressarem na escola, aprendendo o Português como segunda língua durante o processo de escolarização. Segundo estes dados, outros $40 \%$ dos alunos chegam à escola bilíngues (Kaingang e Português) e os demais são falantes apenas do Português e, em geral, adquirem na escola a língua indígena. Quadro semelhante foi anunciado em relação aos professores. Isso coloca um problema, pois a língua indígena é aprendida na comunidade, na casa junto de seus parentes, nos rituais cotidianos, ao redor do fogo, com os mais velhos. Quando a escola passa a ser a instituição que ensina a língua, traz outra realidade a estas comunidades.

O povo Kaingang mostra um sentimento forte em relação a "perda da língua", como se referem diante da predominância do Português em algumas terras indígenas e, principalmente, na faixa etária dos jovens. Sabem que a escola colonizadora tem um papel muito forte nesta "perda" e muitos relatos que registramos nos encontros da ação Saberes Indígenas na Escola evidenciam proibições e humilhações passadas e presentes em relação ao uso da língua originária nos espaços escolares: "quem não fala Português não come a merenda"; "a língua indígena é feia e limitada"; "falar bem o Português para ser civilizado". Mesmo nas escolas atuais, que são denominadas bilíngues, o Português é o idioma corrente das aulas e a língua Kaingang é apresentada em um ou dois períodos por semana, como se fosse uma língua estrangeira.

Em relação aos Guarani que vivem no Rio Grande do Sul, a maior parte das pessoas é falante da língua originária e há uma preocupação explícita das lideranças para que as crianças aprendam o seu idioma como primeira língua. Há um cuidado extremo para evitar que as crianças aprendam o Português muito cedo e é, em geral, na escola que adquirem o Português como segunda língua. Os professores, na sua totalidade, são falantes do idioma originário e, com algumas raras

${ }_{6}$ Cf. https://servicos.educacao.rs.gov.br/pse/srv/estatisticas.jsp?ACAO=acao1. Consulta realizada em 02/08/2019. 
exceções, todos também escrevem em sua língua materna com competência. O idioma corrente da escola Guarani é a sua língua materna.

São realidades linguísticas e culturais distintas, que desde o início da Ação Saberes Indígenas na Escola demandou dois olhares, duas práticas, a fim de dar conta de diferentes cosmovisões. Esse foi um movimento importante, pois a universidade teve que aprender a nomear Kaingang e Guarani, coletivos distintos que se filiaram à instituição ${ }^{7}$. Foi também uma realidade linguística que se revelou na caminhada: os encontros de formação que envolveu o coletivo kaingang, inicialmente eram majoritariamente feitos na Língua Portuguesa e, aos poucos, as falas foram sendo matizadas até chegar um momento de predominância dos idiomas originários, inclusive nas ações desenvolvidas no universo acadêmico.

Nas avaliações realizadas pelos orientadores Kaingang aparece o reconhecimento da ampliação do uso da língua materna, como aparece na fala de Dirceu de Paula, professor orientador da Escola Estadual Indígena Toldo Coroado, situada na Terra Indígena Votouro: "Os professores que antes não falavam a língua estão começando a aprender". Sua fala mostra a ampliação do uso da língua originária no cotidiano escolar. "Com o Saberes, as pessoas passam a ter mais coragem para falar a língua na escola, até na secretaria, até para pedir xerox". A elaboração do material didático no idioma originário foi também uma expressão do apreço ao idioma. "Antes era apenas eu a insistir com o nosso idioma, hoje se somam outras professoras", disse Sueli Krengre Cândido, orientadora kaingang, referindo-se a sua escola e a resistência que ainda se encontra no interior de seu próprio território, um setor da Terra Indígena Guarita. As reflexões sobre a língua Kaingang reverberaram em um movimento coordenado pela linguista Márcia Gojten Nascimento

7 Aos poucos, esse movimento também ocorre nos cursos de graduação da universidade que acolhem estudantes de diferentes povos indígenas: de indígenas passam a ser reconhecidos em sua singularidade identitária. No entanto, uma política de acesso mais restritiva, que limita o ingresso de apenas um aluno indígena por curso a cada ano (contemplando dez vagas) dificulta as identificações entre os próprios estudantes indígenas, mesmo que tenham o mesmo pertencimento étnico.

8 Marcia Gojten Nascimento iniciou um projeto de pesquisa em 2016, través de um diálogo com o povo chamado Māori, da Nova Zelândia, com o objetivo de construir o projeto Kanhgág vĩ mré ẽg jykre pẽ jagfe ("Ninho de Língua e Cultura Kaingang"). O povo Māori tem um programa muito bem-sucedido de transmissão intergeracional do idioma originário, chamado Te Reo Māori, "Ninho de Língua Māori" (Language nest). E assim, começou-se o contato intercultural com esses dois povos interessados no diálogo e na troca de experiências em relação à manutenção 
qual seja realizar um diagnóstico sociolinguístico sobre a situação atual desse idioma nas Terras Kaingang situadas no Rio Grande do Sul. Esse trabalho está recém começando, pois, revela a complexidade que significa mexer na profundidade do falar, do escrever, do fazer e do sentir cultural, individual e coletivo.

Na universidade, línguas quase que desconhecidas começam a ser pronunciadas com a Ação Saberes Indígenas na Escola, despertando curiosidades, admirações e respeito. Há uma crença difundida no sul do Brasil que aqui não há mais "indígenas de verdade", crença que afirma a branquidade de uma região brasileira que, majoritariamente, se julga branca e europeia. Conquanto a presença indígena nos cursos de graduação e pós-graduação da Universidade Federal do Rio Grande do Sul, assegurada pelas políticas afirmativas, ainda é uma presença rara, que representa em geral um aluno ou uma aluna indígena por curso, a Ação Saberes Indígenas na Escola, em encontros que ocorreram nos espaços acadêmicos trouxe coletivos de professores, seus sábios, seus formadores, que se mostraram e fizeram bradar suas vozes.

\section{OS DESAFIOS DE PRODUZIR MATERIAL DIDÁTICO ESPECÍFICO}

O Censo Escolar de 2015, do Ministério da Educação do Brasil, revelou que apenas 53,5\% das escolas indígenas tinha material didático específico. São os dados, mas, -principalmente, o desejo de afirmar culturas, línguas e conhecimentos, que faz indígenas afirmar a necessidade de produzir materiais didáticos que deem conta de cada singularidade, representada por mais de 300 povos, com cerca de 180 línguas distintas, segundo os dados do IBGE (2010) ${ }^{9}$. É um movimento que vem ao encontro de um dos objetivos da Ação Saberes Indígenas na Escola, qual seja o de "fomentar pesquisas que resultem na elaboração de materiais didáticos e paradidáticos em diversas linguagens, bilíngues e monolíngues, conforme a situação sociolinguística e de acordo com as especificidades da educação escolar indígena" (BRASIL, 2013, s.p.).

Portanto, o desafio de produzir materiais didáticos próprios, que conduza a um afastamento do que se faz nacionalmente pelo Programa Nacional de Livro

de suas línguas (Kaingang e māori), em prol das línguas ameaçadas. Este trabalho foi trazido pela linguista Kaingang para a Ação Saberes Indígenas na Escola, enriquecendo as reflexões, abrindo caminhos para outras ações que afirmam e revigoram o idioma deste povo.

9 https://indigenas.ibge.gov.br/graficos-e-tabelas-2.html. Consulta realizada em 02/08/2019. 
Didático (PNLD), que, não obstante as grandes vantagens de qualificar e unificar os livros didáticos usados em todas as escolas públicas do país, reforça a homogeneidade escolar que suplanta diferenças. Mas também o desafio de ter nas escolas materiais didáticos nas línguas próprias e, no caso do Núcleo UFRGS da Ação Saberes Indígenas, produzir materiais que respeitassem as vontades e processos próprios Kaingang e Guarani e que fossem de qualidade. Também nos damos conta neste processo, que o material didático não vem sozinho. Era fundamental pensar metodologias próprias de aprendizagens, pois do contrário os materiais, mesmo diferenciados, entram na mesma lógica que se busca desconstruir. Para isso, muitos encontros foram dedicados para tal realização, em um esforço coletivo que resultou na produção compartilhada entre equipe da universidade e equipe indígena. Nas escolas Kaingang e Guarani, nos encontros de estudo dos pequenos grupos, borbulhavam materiais diversos que poderiam resultar em muitos livros, alguns talvez seguindo o modelo de cartilhas de alfabetização, comuns na Língua Portuguesa. Este fato evidencia o quanto a escola ocidental e seus modelos de ensino-aprendizagem está internalizada nos modos de ser professor.

Os questionamentos e as reflexões faziam abrir outros caminhos que conduziu a um primeiro resultado concreto: a produção e publicação impressa de um livro no idioma Guarani intitulado Jereroayu: Textos da tradição oral Guarani-Mbya. Estes kaxo foram narrados pelo Moramoĩ Turíbio Gomes e pela Mborojaryi Laurinda Borges, em encontros com todos os professores e tentavam criar um espaço apropriado de existência, em rodas em torno do fogo, à noite e ao amanhecer. Reuniram assim uma quantidade considerável de narrativas e, com os mais velhos, os professores Guarani refletiam e decidiam sobre a publicação: o que pode ser publicado, o que pode ser revelado, e a decisão de uma publicação monolíngue. Há, entre os Guarani, um cuidado muito grande com a dimensão do segredo, que protege o que é sagrado, que decide o que pode ser contado ao não indígena, o que pode ir para a escola, os saberes que são próprios dos cerimoniais na Opy e por isso, um trâmite de reflexão, de consultas, para enfim chegar a decisão. É dessa forma que resistem, existem e (re)existem há tantos séculos. Após um intenso trabalho, que implicou ações, reflexões, paradas, retomadas, eis o primeiro resultado: foram produzidos 800 exemplares e mais um e-book, distribuído nas escolas e nas comunidades Guarani do Rio Grande do Sul. 
Pelos professores Kaingang, também foi produzido um livro intitulado Kanhgág Vĩ Ki Kanhrãn-Rãn Fã Ag Rãnhrãj, versão impressa. Com mil exemplares e versão e-book. Acompanhou este primeiro livro um CD de músicas kaingang, fruto da pesquisa profunda coordenada pela professora Ilva Maria Emílio, da Escola Antônio Kasĩn-Mĩg, orientadora de um grupo Kaingang em um dos setores da Terra Indígena Guarita. Eram canções esquecidas e que, com uma busca sensível, impulsionada pelo aguçado senso de pesquisa e pela disposição ético- política de Ilva, puderam ser recuperadas e gravadas para circular nas escolas e nas comunidades Kaingang. Um grupo de pessoas da Terra Indígena Guarita envolvidas neste trabalho específico dos cantos fizeram a gravação no estúdio da Faculdade de Música da Universidade Federal do Rio Grande do Sul. Além do livro e do $C D$, também foi publicado nesse primeiro conjunto de materiais didáticos o que se chamou de "fichas de alfabetização na Língua Kaingang", contendo um alfabeto específico em letras grandes e destacáveis para serem manuseadas nas escolas. Todos os materiais foram distribuídos às escolas indígenas do estado, pela Secretaria de Estado da Educação, parceira nesta rede desde o início da Ação.

Enquanto o primeiro conjunto de materiais didáticos realizados deu ênfase aos processos de alfabetização nas línguas maternas, o segundo conjunto foi pensado em constituir-se num auxiliar deste processo, mas que contemplasse outros formatos, a fim de atingir uma gama ampliada de idades e aproximar-se das pedagogias próprias indígenas e dos processos políticos pelos quais as populações estão inseridas.

Os materiais utilizam outros formatos não restritos à linguagem escrita, contendo imagens, ilustrações, cartografias e sons. Tais materiais foram produzidos pelos professores, com auxílio técnico e empréstimo da universidade de ferramentas de trabalho como gravadores, câmeras fotográficas e materiais de escrita. As diferentes linguagens refletem os desafios de não pensar a escola como o lugar da escrita, mas também como uma abertura à oralidade. Assim, os orientadores demandaram mais tempo para que as comunidades fossem envolvidas nos processos de construção do material, bem como os professores cursistas engajados em realizar pesquisas e participarem das decisões sobre o material. Foi um material mais complexo, que envolveu encontros nas comunidades entre orientadores e cursistas, reuniões entre orientadores para decisão, processo de pesquisa e coleta de materiais fotográficos e sonoros, edição e design, tiveram outro tempo de realização, priorizando as discussões, detalhes, idas e vindas à comunidades e revisão atenta. O exercício de 
produção destes materiais nos mostrava que, mais importante que o resultado, era o próprio processo, as vivências, negociações e reflexões sobre aprendizagem e ensino, metodologias que se produziram durante os encontros.

Figura 2 - Mapas de seus territórios desenhados pelos Guarani

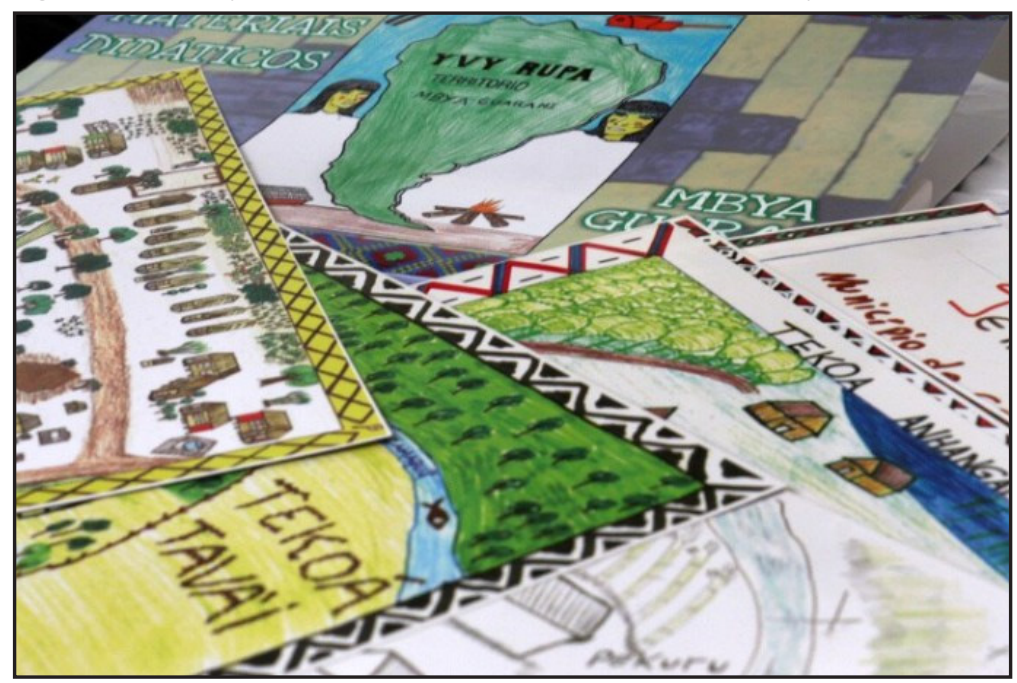

Fonte: Arquivo da Ação Saberes Indígenas na Escola/UFRGS.

Figura 3 - Material didático Kaingang: CD de narrativas e cantos, fichas temáticas com imagens fotográficas
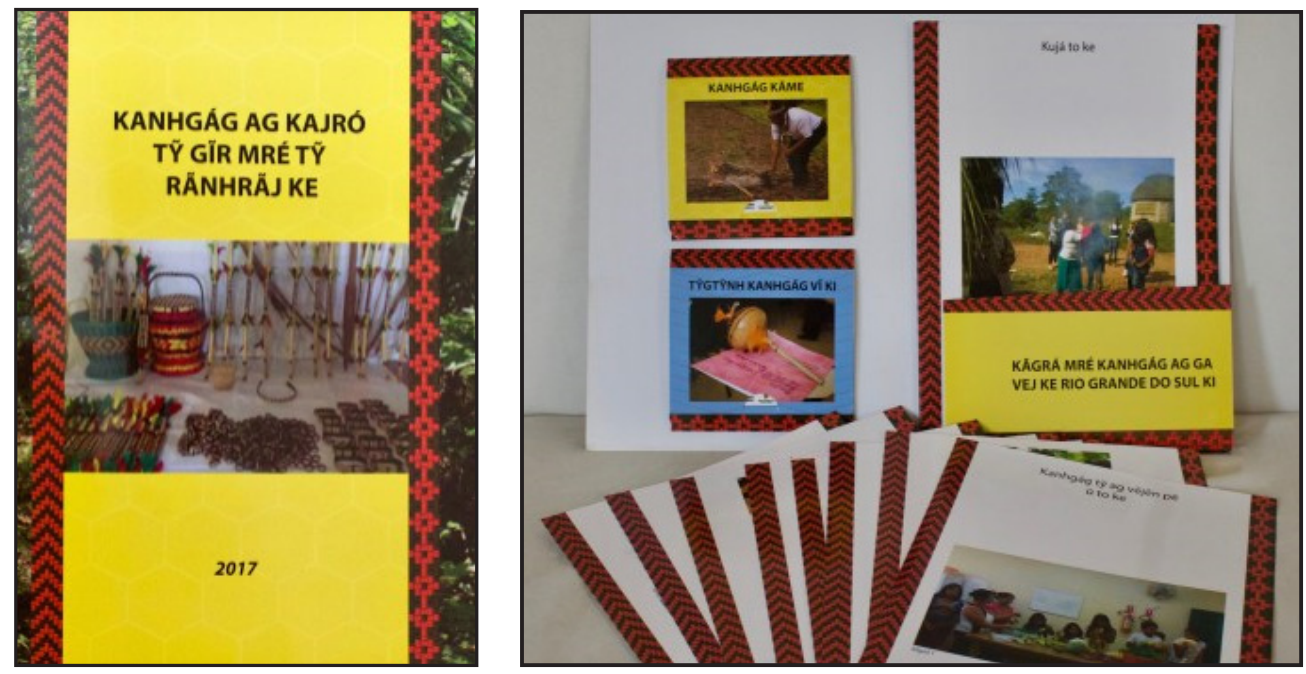

Fonte: Arquivo da Ação Saberes Indígenas na Escola/UFRGS. 
A qualificação do material didático se faz como processo de formação do grupo, num incessante ir e vir: elaborar, olhar o que já foi feito, refazer a partir das reflexões com as pessoas mais velhas da comunidade, com os demais professores, com o grupo da universidade. Também em relação a utilização destes materiais nas escolas e comunidades, a diversificação de linguagens permite um uso mais ampliado. Foi tão intenso o processo de elaboração do segundo conjunto de materiais didáticos, com um resultado primoroso, que se decidiu por fazer uma segunda edição do mesmo material, ampliando a quantidade para uma consequente utilização por um grupo mais ampliado de pessoas e coletivos Kaingang e Guarani.

Outro movimento importante a destacar foram os eventos para o lançamento dos materiais, tanto na universidade, quanto em cada comunidade escolar. Para o lançamento na universidade, além de uma cerimônia organizada a partir das recomendações dos Kaingang e Guarani que incluía a participação de nossas autoridades, primamos por produzir notícias que divulgassem, tanto a Ação Saberes Indígenas na Escola, como os produtos qualificados que resultaram do trabalho conjunto e intercultural: a universidade foi a sustentação estrutural e material; os Kaingang e Guarani foram os criadores intelectuais das publicações. Consideramos que essa ritualização promoveu um reforço da autoestima e, principalmente entre os kaingang, em cada comunidade o lançamento foi apoiado por aportes de recurso de custeio da Ação Saberes Indígenas na Escola, concretizando-se como um evento ritualizado.

\section{COMO REPERCUTE A AÇÃO SABERES INDÍGENAS NOS TERRITÓRIOS INDÍGENAS}

A teoria Indígena surge dentro de um campo multiénico complexo - em relação à sua construção epistemologica e a partir de sua prática política - está ligada à apropriação crítica dos sistemas externos de conhecimento, enquadrados pelo pensamento próprio (RAPPAPORT; PACHO, 2005 p. 29). O estar junto dos Kaingang e Guarani, de maneira especial com os mais velhos, conhecedores dos processos próprios de educar conforme a tradição, a possibilidade de convivência entre professores, os velhos e os sábios e os não indígenas foi(é) de extrema importância na caminhada de construção do processo de formação continuada da 
Ação Saberes Indígenas na Escola. "A minha escola está no mato" ${ }^{10}$ (fala do Kujá Jorge Garcia), a "casa de reza é nossa escola" (expressão reiterada dos Guarani), são falas que indicam que os conhecimentos escolares precisar estar fundamentados na reciprocidade e na ética indígena, em uma construção que aponta para a inter-relação e interdependência entre todos os sujeitos que participam deste processo formativo. Ela propicia e fundamenta os compromissos, cuidados mútuo, a cooperação e troca de saberes e conhecimentos entre os sujeitos, elementos importantes para (re)existência.

Relembrar aqui as falas dos(as) velhos(as) indígenas, mostra que para além da escola, outros espaços são importantes e que se comunicam profundamente com os saberes indígenas da comunidade. As atividades dos professores Kaingang e Guarani, como a conta-ação de história, cantos e danças, pintura de grafismo corporal vão se desenhando nos entornos escolares, fazendo parte de vivências que acontecem nas terras indígenas. Nesse sentido, a Ação Saberes Indígenas na Escola produz efeito de retrovisor, pois ao "olhar para frente se enxerga o que está atrás": a ancestralidade, que assume significados importantes a partir das práticas que acontece dentro e fora da escola, numa clara expressão de que os saberes indígenas estão muito presentes em outros espaços e em todos os sujeitos das comunidades Kaingang e Guarani.

É importante dizer que o deslocamento das práticas para além dos tempos e espaços escolares atinge a todos dentro das comunidades indígenas. Os velhos e as velhas, portadores de conhecimentos ancestrais, manifestam a alegria de sentirem-se novamente valorizados, fato este evidenciado no canto romântico Kaingang "Sãpe Tánh"11, recuperado pela orientadora de estudo Ilva Maria Emilio e os professores de seu grupo. Além disso, os orientadores de estudos, junto dos professores, vão também recuperando narrativas educativas já esquecidas pelos jovens, mas que estão presentes na memória dos(as) velhos(a)s indígenas. Percebemos, mais uma vez, que só bastava provocar essas memórias para que elas voltassem a ecoar nos espaços

\footnotetext{
${ }^{10}$ Kujá Jorge Garcia, numa de suas conta-ação nas atividades de formação, conta que sua escola é do mato, em que tudo que sabe aprendeu neste espaço e que tinha medo da escola que ensinava ler e escrever. Mas que agora ela devia ser uma ferramenta dos kaingang.

${ }^{11}$ Canto Sãpe Tánh, antigamente cantado pelas mulheres kaingang, em que colocavam o seu desejo não largar seu homem (namorado), mas não sendo correspondida ela tomava a decisão de ir embora. Geralmente era cantado pelas mulheres solteiras.
} 
das comunidades. Entre tantas, citamos a narrativa recuperada pela orientadora Iraci Grẽja Antônio, Kamẽ mré Kajru Vẽnhprũg, que fala dos casamentos tradicionais Kaingang e sua importância para a manutenção do povo e sua tradição. Outro saber indígena Guarani importante, trazido pelo professor Guarani Joel Pereira, o Nhemongueta ${ }^{12}$, que recupera o modo de convivência desse povo.

Nesse sentido, talvez, seja importante refletir sobre o papel da escola, diante dos saberes indígenas, pois, parece que a estrutura de escola que predomina hoje tem dificultado o transito desses saberes em seus componentes curriculares. "A escola de feição europeia tem uma finalidade determinada: formar cidadãos tecnicamente qualificados e úteis ao mercado de trabalho, bem como súditos obedientes ao modelo político que sustenta o modelo econômico em vigor" (LUCIANO, 2013, p. 109). A importância dos processos escolares não poderia estar centrada em conteúdos já prontos, distantes dos saberes da comunidade, e por isso nos perguntamos: onde estão os saberes vindos da "escola do mato" e das "casas de rezas"? Ou estes possuem lugar próprio? Nesse sentido, devemos pensar a educação escolar permeada pela sensibilidade, pelos encantamentos e não apenas pela razão central e quase única na escola ocidental. É fundamental reconhecer, junto de cada participante das formações, a importância dos saberes presentes nos diversos espaços de construção de conhecimentos, evidenciando que não é só a escola que é um espaço importante, mas todos os espaços espaIhados nas comunidades indígenas, que expressam o bem-viver. Neste contexto, a existência de diversas visões de mundo, outras epistemologias, de uma abertura a novas formas de conhecer, de compartilhar a diversidade de saberes existentes e suas construções é fundamental. A Ação Saberes Indígenas na Escola foi/é um processo de construção coletiva, de um caminhar juntos, que nos permite perceber os (des)entendimentos e inquietações que moveram/movem os professores indígenas e não indígenas.

O reconhecimento, por parte dos professores, da ausência dos conhecimentos indígenas, do pouco das histórias e culturas do indígena na vida da escola

\footnotetext{
${ }^{12}$ Nhemongueta, narrado pela Dona Laurinda e seu Turíbio, velhos sábios Guarani que acompanharam a Ação saberes Indígenas na Escola. Segundo eles, são modo de convivência, momento em que toda família se senta em redor do fogo para o mais velho ou até mesmo o pai passar aconselhamento aos filhos, sobre os cuidados dos jovens que recém passaram da fase criança para vida adulta, a fim de não ser pego pelos espíritos dos animais.
} 
foi importante, pois desencadeou mudanças. O reconhecimento de desejos, de busca de fundamentação a práticas docentes, gerou aberturas e uma dedicação profunda para buscar novas formas de produção de conhecimentos, em relação com as já conhecidas. Assim, assumiu-se o desafio da construção de propostas político-pedagógicas próprias e diferenciadas, tendo a consciência de que a cultura dos povos indígenas estava/está também inserida numa relação acadêmica e escolar colonizadora. Nesse sentido, acreditamos que os professores Kaingang e Guarani, referenciados no movimento provocado pelas formações durante a Ação Saberes Indígenas na Escola, podem construir uma proposta sensível, transformadora, politizada e emancipatória, que lhes permite o rompimento com condutas individualistas e colonizadoras, criando assim interatividades entre os professores e suas comunidades.

A consciência crítica de nosso fazer pedagógico nos compromete a buscar permanentemente o aperfeiçoamento de nossos jeitos de ensinar, para manter os conhecimentos e saberes milenares construídos na cultura. Acreditamos que isto deva ser um ato prazeroso, de descobertas para as transformações pedagógicas necessárias dentro de uma prática de investigação. Nesse sentido, os professores e suas comunidades assumem a perspectiva de buscar e conhecer as boas práticas que os indígenas alimentam dentro de suas comunidades. É necessário também refletir a relação com a sociedade não indígena e o Estado, articulando tempo espaço: passado, presente e futuro, para conhecer e construir narrativas dentro e fora da escola oficial, o nosso kanhkã ${ }^{13}$ que é o que pode sustentar a escola.

Por fim, a Ação Saberes Indígenas na Escola fez eco por todos os espaços das comunidades indígenas Kaingang e Guarani. Seus cantos, narrativas, provocados por metodologias vindas dos saberes presentes nos velhos, ora adormecidos, fortaleceram a identidade, provocando e afirmando o orgulho de serem indígenas, povos detentores de conhecimentos, produzidos na coletividade, e capazes de superar o individualismo produzido pela escola colonizadora implantada em suas terras.

\footnotetext{
${ }^{13}$ Kanhkã - palavra Kaingang recuperada pelos orientadores de estudo nas rodas de conversas nas noites dos encontros de formação. Aquilo que sustenta: céu, parente, tempo-espaço, presente, passado e futuro, bem-viver.
} 


\section{REFERÊNCIAS}

ALBAN ACHINTE, Adolfo. Pedagogías de la re-existencia: artistas indígenas e afrocolombianos. In: WALSH, Catherine (Org.). Pedagogías Decoloniales - prácticas insurgentes de resistir, (re)existir y (re)vivir. Quito/Ecuador: Abya-Yala, 2017. p. 443-68. (Série Pensamento decolonial, Tomo I e II).

BRASIL. Ministério de Educação. Portaria n. 1.061, de 30 de outubro de 2013. Institui a Ação Saberes Indígenas na Escola. Brasília-DF, 2013.

FORNET-BETANCOURT, Raúl. Filosofar para nuestro tiempo en clave intercultural. Concordia, Reihe Monographien, Band 37, Aachen, 2004.

IBGE. Indígenas. Brasília-DF: IBGE, 2010. Disponível em: https://indigenas.ibge.gov.br/ graficos-e-tabelas-2.html. Acesso em: 15 mar. 2020

KUSCH, Rodolfo. El Pensamiento Indígena y Popular en America. Provincia de Santa Fé, AR: Editorial Fundación Ross, 2000. p. 255-546. [Obras completas, Tomo II].

KUSCH, Rodolfo. Geocultura del hombre americano. Buenos Aires: Colección Estudios Latinoamericanos, [s.I.], 1976.

LUCIANO, Gersem José dos Santos. Educação para o manejo do mundo: entre a escola ideal e a escola real. Os dilemas da educação escolar indígena no Alto Rio Negro. Rio de Janeiro: Contra Capa: Laced, 2013.

MATO, Daniel. No hay saber "universal", la colaboración intercultural es imprescindible. Alteridades, México, v. 18, n. 35, p. 101-116, 2008.

RAPPAPORT, Joanne; PACHO, Abelardo Ramos. Una historia colaborativa: retos para el diálogo indígena-académico. Revista Historia Crítica, Bogotá, n. 29, jan./jun. 2005.

SANTOS, Boaventura de Souza. Descolonizar el saber, reinventar el poder. Montevideo: Ediciones Trilce, 2010.

WALSH, Catherine. Notas pedagógicas a partir das brechas decoloniais. In: CANDAU, Vera Maria (Org.). Interculturalizar, descolonizar, democratizar: uma educação "outra"? Rio de Janeiro: 7Letras, 2016. p. 64-75. 


\section{Sobre os autores:}

Bruno Ferreira: Doutor em educação pela Universidade Federal do Rio Grande do Sul. Integra a coordenação da Ação Saberes Indígenas na Escola, núcleo da Universidade Federal do Rio Grande do Sul (UFRGS). Professor de História no Instituto Estadual de Educação Indígena Angelo Manhká Miguel, Terra Indígena Inhacorá, São Valério do Sul, RS, Brasil. E-mail: brunokaingang@yahoo.com.br, Orcid: http://orcid.org/0000-0003-0475-8727

Magali Mendes de Menezes: Doutora em Filosofia. Professora e pesquisadora no Programa de Pós-Graduação em Educação da Universidade Federal do Rio Grande do Sul (UFRGS). Coordenadora da Ação Saberes Indígenas na escola/UFRGS. E-mail: magaliufrgs@gmail.com, Orcid: https://orcid.org/0000-0001-6325-9595

Maria Aparecida Bergamaschi: Doutora em educação. Professora e pesquisadora na Faculdade de Educação e no Programa de Pós-graduação em Educação da Universidade Federal do Rio Grande do Sul (UFRGS). Líder do Grupo de Pesquisa PEABIRU: Educação Ameríndia e Interculturalidade (CNPq). Integra a coordenação da Ação Saberes Indígenas na Escola, núcleo UFRGS. E-mail: cida.bergamaschi@gmail.com, Orcid: https://orcid.org/0000-0002-6028-4039

Recebido em: 20 de maio de 2020

Aprovado para publicação em: 31 de outubro de 2020 
